\title{
INFLUENCE OF INTRASPECIFIC COMPETITION FOR FOOD ON THE BODYWEIGHT OF THE ADULT APHIDOPHAGOUS LADYBIRD, COCCINELLA TRANSVERSALIS
}

\author{
AHMAD PERVEZ* and RUPALI SHARMA \\ Biocontrol laboratory, Department of Zoology, Radhey Hari Govt. P.G. College, Kashipur, Udham Singh Nagar, Uttarakhand, India \\ *Corresponding author: ahmadpervez@yahoo.com
}

\section{ABSTRACT}

\begin{abstract}
Aggregation of conspecific predators sharing a common prey, influences their bodyweights. We investigated the influence of intraspecific competition of adult ladybirds of Coccinella transversalis Fabricius on their bodyweight feeding on rusty plum aphid, Hysteroneura setariae (Thomas). Adult males and females consumed a significantly greater number of aphids with increase in predator-density, however, the aphid-consumption per predator declined with this increase. The weight gain per predator also decreased linearly with increase in the density of both male and female predators. This indicates that the weight-gain of the predator is a function of the prey consumed. The searching efficiency decreased with increase in predator density due to mutual inference. The mutual interference constants for adult male and female ladybirds were -0.419 and -0.546 , respectively. The females consumed a greater number of aphids than males. The killing power of the ladybird denoted by the k-value increased curvilinearly with increase in predator density. We conclude that prey consumption is a function of body size and that the offspring of those that aggregate at low densities in prey-rich habitats develop into large adults.
\end{abstract}

Keywords: conspecific predator; Coccinella transversalis; intraspecific competition; ladybirds; numerical response

\section{Introduction}

Knowledge of the predator-prey interactions of predatory ladybirds (Coccinellidae: Coleoptera) is important for understanding their effectiveness in the biocontrol of aphids. Quantitative estimates of ladybirds' searching efficiency and prey consumption at varying prey-densities indicate their potential as biocontrol agents (Bayoumy 2011; Bayoumy and Michaud 2012). This predator's functional response to the changes in prey density indicates density-dependent prey consumption (Holling 1959). However, the effect of predator density on prey density may also help predict biocontrol outcomes, estimate the effect of intraspecific competition and interferences among ladybirds. The density-dependent predator-prey dynamics is described by numerous models (Pervez et al. 2018), of which the classical Nicholson and Bailey (1935) model defines "area of discovery", as a crucial parameter determining the searching efficiency of a predator. An inductive model (Hassell and Varley 1969) including the mutual interference constant (Hassell 1971; Bayoumy et al. 2014), further simplifies this model and indicates that the predator's searching efficiency declines with increase in its density. These models advocate predation to be a function of both prey-and predator-dependent processes and account for the effect of mutual interference on prey consumption. This interference alters ladybird's foraging success or may compensate for the decline in foraging activity due to the time required for digestion at high prey densities (Papanikolaou et al. 2016). Kindlmann and Dixon (1993) questioned the biocontrol potential of aphidophagous ladybirds stating that even optimal foraging and laying of eggs may only result in a slight reduction of aphid abundance. Furthermore, the adults should maximize their fitness by deciding whether to stay in or leave an aphid-patch (Kindlmann and Dixon 2010). In addition, greater generation-time ratio of ladybirds makes them slow developers, thereby impeding the top-down regulation of aphid abundance (Kindlmann and Dixon 1999, 2001, 2015). Kindlmann et al. (2020) further concluded that it is generation-time ratio rather than voracity that drives the dynamics of insect-natural enemy systems, particularly aphid-ladybird system.

Predaceous ladybirds (Coleoptera: Coccinellidae) are potential biological control agents, as they prey upon numerous coccid and aphid pests (Hodek et al. 2012; Omkar and Pervez 2016; Pervez et al. 2020). They switch from extensive search to intensive search after capturing a prey (Pervez and Yadav 2018). Complex plant morphology further modifies intensive search (Legrand and Barbosa 2003). Mutual interactions impede their consumption of prey and searching efficiency (Omkar and Pervez 2004a; Bayoumy and Michaud 2012). Their searching efficiency and incidence of mutual interference might be dependent on the type of prey (Al-Deghairi et al. 2014). These coccinellid predators may switch from a rare stage of prey to an abundant stage of prey (Fathipour et al. 2020) thereby suppressing prey-abundance and increasing their body size. Dixon (2000) opined that variation in body-size within the species and gender might be associated with the relative effects of food quality and quantity. Furthermore, smaller-sized ladybirds may exploit the aphid colonies earlier, which may later be overtaken by the large ladybirds when aphid densities increase (Dixon 2007). Sloggett (2008) argued that ladybirds' body size might not be just a function of aphid density, but other complex interactions between density and prey size are also operational. This further raises the question of whether con- 
tinuous exposure of aphidophagous ladybirds to aphid abundance may increase the growth rate and have evolutionary significance. Most species with high biocontrol potential are large and highly fecund, which are favoured by natural selection, particularly in food-abundant habitats (Brown and Sibly 2006). Large species have a reproductive advantage over smaller indigenous species in prey-rich habitats (Kajita and Evans 2010).

Coccinella transversalis Fabricius is a predator (Coleoptera: Coccinellidae) of many insects and acarine pests, particularly, aphids (Omkar and James 2004; Omkar and Pervez 2004b; Maurice et al. 2011). Manipulation of its reproductive parameters may promote its abundance (Michaud et al. 2013). It coexists with other coccinellids and mostly dominates the aphid predatory guild (Omkar et al. 2005a, b) and together with coccinellid, Propylea dissecta (Mulsant) may synergistically suppress populations of Aphis gossypii (Glover) (Omkar and Pervez 2011). We found adults and larvae of $C$. transversalis preying on rusty plum aphid, Hysteroneura setariae (Thomas) infesting creeping bluegrass, Bothriochloa insculpta (Hochst.). This aphid is a cereal pest, attacking rice, wheat, sugar cane, maize and soya bean crops on the Indian sub-continent (Kale et al. 2020). In a banker plant system, H. setariae reared on grasses, can be used as a non-pest prey to build-up ladybird populations (Rattanpun 2017). Hence, we designed a laboratory experiment to determine (i) the searching efficiency of adult male and female C. transversalis feeding on $H$. setariae (ii) killing power of adult ladybirds associated with their aggregation, and (iii) the influence of the intraspecific competition for food on the adult bodyweight and its implications.

\section{Materials and Methods}

\section{Insect culture and maintenance}

We sampled and collected adults of $C$. transversalis from $H$. setariae infested fields of $B$. insculpta near our college campus, Kashipur, India $\left(30.2937^{\circ} \mathrm{N}, 79.5603^{\circ} \mathrm{E}\right)$. We brought them to the laboratory and paired adult male and female ladybirds in Petri dishes $(9.0 \mathrm{~cm}$ diameter $x$ $2.0 \mathrm{~cm}$ height) containing an ad libitum amount of $H$. setariae infesting host plant twigs. The females mated and laid eggs in clusters that were isolated and kept in other Petri dishes (size as above). We transferred these Petri dishes to an Environmental Test Chamber (ETC) (REMI, Remi Instruments), maintained at $25 \pm 1{ }^{\circ} \mathrm{C}, 65 \pm 5 \%$ R.H and $12 \mathrm{~L}: 12 \mathrm{D}$. The eggs hatched and the first instar larvae were placed in $500 \mathrm{ml}$ Borosil glass beakers containing sufficient supply of aphid infested twigs. Five first-instar larvae were kept in each beaker and reared on aphids until adult emergence. We replenished the aphids daily to avoid contamination. The newly eclosed $\mathrm{F}_{1}$ adults were sexed and isolated in separate Petri dishes, (size as above) for use in the experiments.

\section{Experimental design}

Fifteen-day-old adult male C. transversalis was taken from the stock and starved for 12 hours to standardize its hunger. Thereafter, we weighed it $\left(\mathrm{W}_{1}\right)$ using an electronic balance (SHIMADZU, Model ATX-224, $0.1 \mathrm{mg}$ precision) and kept it in a 500ml glass beaker containing 200 third-instar nymphs of $H$. setariae (as prey). A piece of folded moist filter paper was also kept in the beaker to provide moisture. We covered the beaker with fine muslin cloth fastened by a rubber band. We transferred this beaker to ETC maintained at the abiotic conditions mentioned above. After 3 hours of exposure, we removed the beaker from ETC and counted the number of live aphids to determine the number of aphids consumed $\left(\mathrm{N}_{\mathrm{a}}\right)$. The ladybird was weighed again $\left(\mathrm{W}_{2}\right)$ (as above) to estimate the gain in weight $\left(\mathrm{W}_{\mathrm{e}}=\mathrm{W}_{2}-\mathrm{W}_{1}\right.$, i.e. final weight of adult - the initial weight of adult). This experiment was replicated ten times $(n=10)$. We repeated the experiment at predator densities of 2, 4, 8, and 10. Thereafter, the entire experiment was repeated using the above predator densities of 15-day-old adult female C. transversalis. The data were subjected to the following data analysis.

\section{Data analysis}

Nicholson-Bailey model gave the following equations (1) and (2):

$$
\begin{aligned}
& N(t+1)=\lambda N(t) \exp [-a P(t)] \\
& P(t+1)=c N(t)[1-\exp (-a P(t))]
\end{aligned}
$$

where $N(t)$ is the number of hosts (prey) at time $t, \mathrm{P}(t)$, the number of predators at time $t, \lambda$ is the host reproductive rate, and a is the area of discovery. To estimate the area of discovery, the above model (2) can be rearranged (Hassel 1978) after assuming that $c=1$, as:

$$
a=\frac{1}{P} \log e \frac{N}{(N-N a)}
$$

where $a$ is the area of discovery, $N$ is the initial aphid density, $\mathrm{Na}$ is the number of aphids consumed, and $P$ is the predator density. We used the above-rearranged model (3) to relate the area of discovery to prey density. After estimating the area of discovery, Hassell and Varley (1969) model (equation 4) was used to estimate Quest constant $(Q)$, while mutual interference $(m)$ constant was determined from the slope of regression of log a (area of discovery) on $\log P$ (predator density).

$$
a=Q P^{-m}
$$

Equation (4) can be linearized by using logarithms as follows:

$\log a=\log Q-m \log P$ 

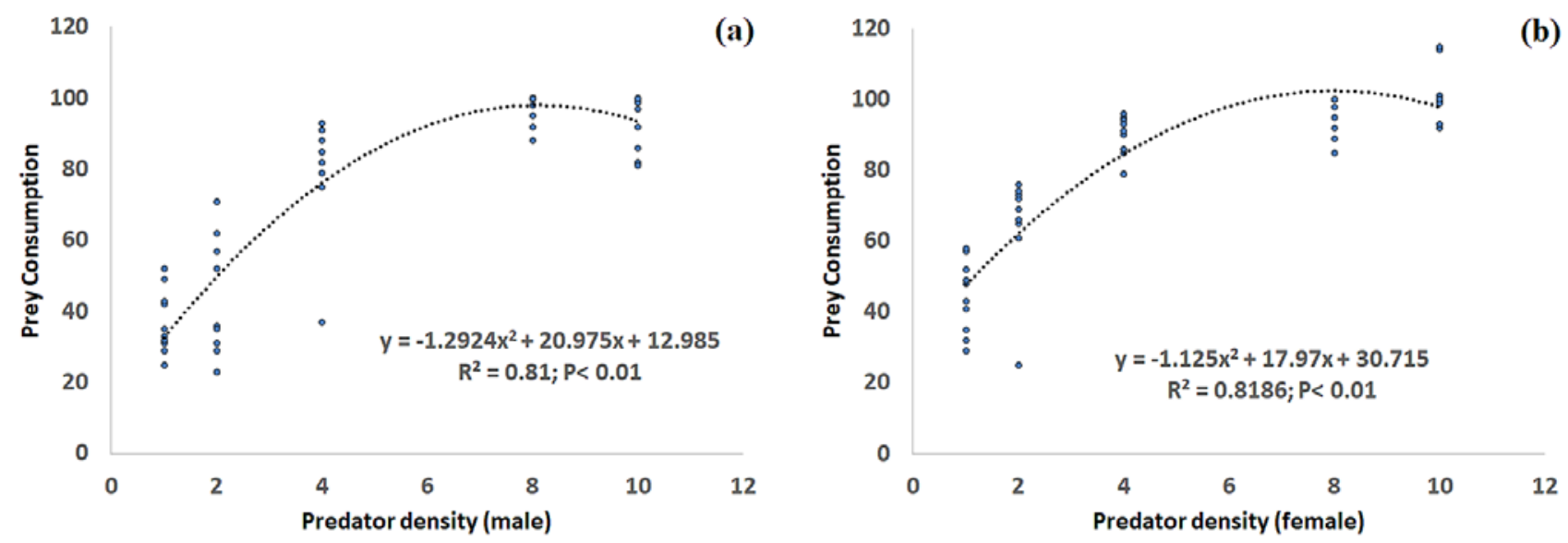

Fig. 1 Relationship between prey consumption and predator density for (a) male and (b) female C. transversalis fed the aphid, H. setariae.

$k$-value, which is the measure of the 'killing power' (Ooi 1980) was also estimated by taking the difference between the logarithms of aphid population before and after prey consumption (Varley et al. 1973) at various predator densities using equation (6).

$$
k \text {-value }=\log _{10}(N / S)
$$

The number of prey consumed per predator by adult male and female ladybirds at different predator densities was subjected to one-way ANOVA using statistical software SAS 9.0 (SAS 2002). The means were compared using Tukey's test of significance. We also subjected the prey consumed per predator at particular predator densities for both adult male and female ladybirds to a two-sample t-test using SAS 9.0. All data were tested for normality and variances using the Shapiro-Wilk test. The (i) prey consumption, (ii) area of discovery, (iii) killing power and (iv) mean weight gained or weight gained per predator with the increase in predator density were further subjected to regression analysis to discover the relationship between these variables using SAS 9.0. The log area of discovery and the log predator density were subjected to linear regression in order to determine the mutual interference and Quest constants using SAS 9.0.

\section{Results}

The prey consumption of the adult male and female C. transversalis increased curvilinearly with increase in predator density (Fig. 1). The female ladybirds consumed a significantly greater number of aphids than the males $(\mathrm{t}=3.95 ; \mathrm{P}<0.01 ; \mathrm{d}$. $\mathrm{f} .=94)$. The prey consumption per predator decreased significantly with increase in predator density (Table 1). The difference in the prey consumption of males and females was only significant when the number of ladybirds was two $(t=-3.11 ; P<0.01$; d. f. $=17)$ and ten $(t=-2.27 ; P<0.05 ; \mathrm{d}$. f. $=17)$ (Table 1$)$. The area of discovery of male and female beetles decreased with increase in predator density (Fig. 2). The log values of area of discovery of male $\left(r^{2}=0.5703 ; P<0.05\right)$ and female $\left(r^{2}=0.8099 ; P<0.01\right)$ beetles showed a significant linear relationship with increase in log predator density $(P<0.01)$. The mutual interference constants for adult

Table 1 Prey consumption per adult male and female $C$. transversalis at various predator densities.

\begin{tabular}{|c|c|c|c|c|c|}
\hline Predator density & Adult Female & Adult male & t-value & P-value & d. f. \\
\hline 1 & $44.40 \pm 10.16 a$ & $37.10 \pm 8.93 \mathrm{a}$ & -1.71 & 0.160 & 17 \\
\hline 2 & $32.10 \pm 7.37 b$ & $20.95 \pm 8.60 b$ & -3.11 & $<0.010$ & 17 \\
\hline 4 & $22.20 \pm 1.57 c$ & $20.08 \pm 4.07 b$ & -1.58 & 0.148 & 17 \\
\hline 8 & $11.90 \pm 0.69 d$ & $12.16 \pm 0.53 c$ & 0.64 & 0.533 & 16 \\
\hline 10 & $10.14 \pm 0.76 d$ & $9.36 \pm 0.78 c$ & -2.27 & $<0.05$ & 17 \\
\hline F-value & 63.74 & 34.15 & & & \\
\hline P-value & $P<0.0001$ & $P<0.0001$ & & & \\
\hline d. f. & 4,49 & 4,49 & & & \\
\hline
\end{tabular}

Data are Mean \pm S.D.; Tukey's range $=4.02$

Means compared by using different letters in rows or columns to denote statistically significant differences. 

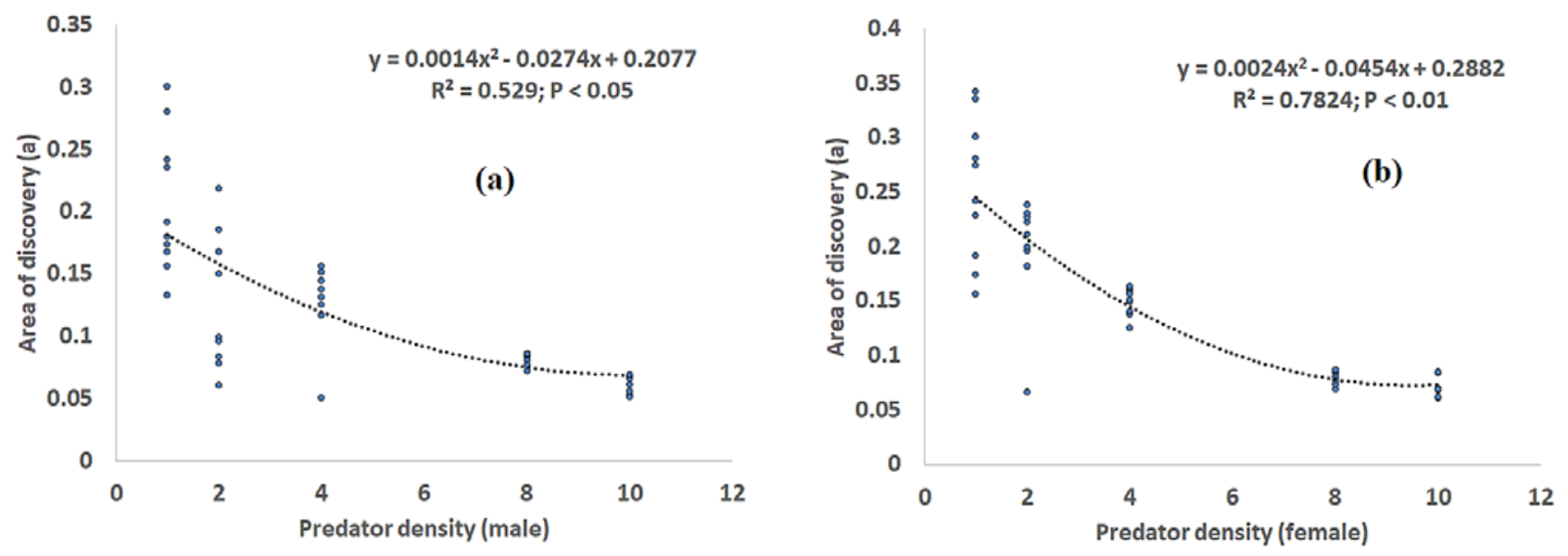

Fig. 2 Relationship between area of discovery and predator density for (a) male and (b) female C. transversalis fed the aphid, H. setariae.
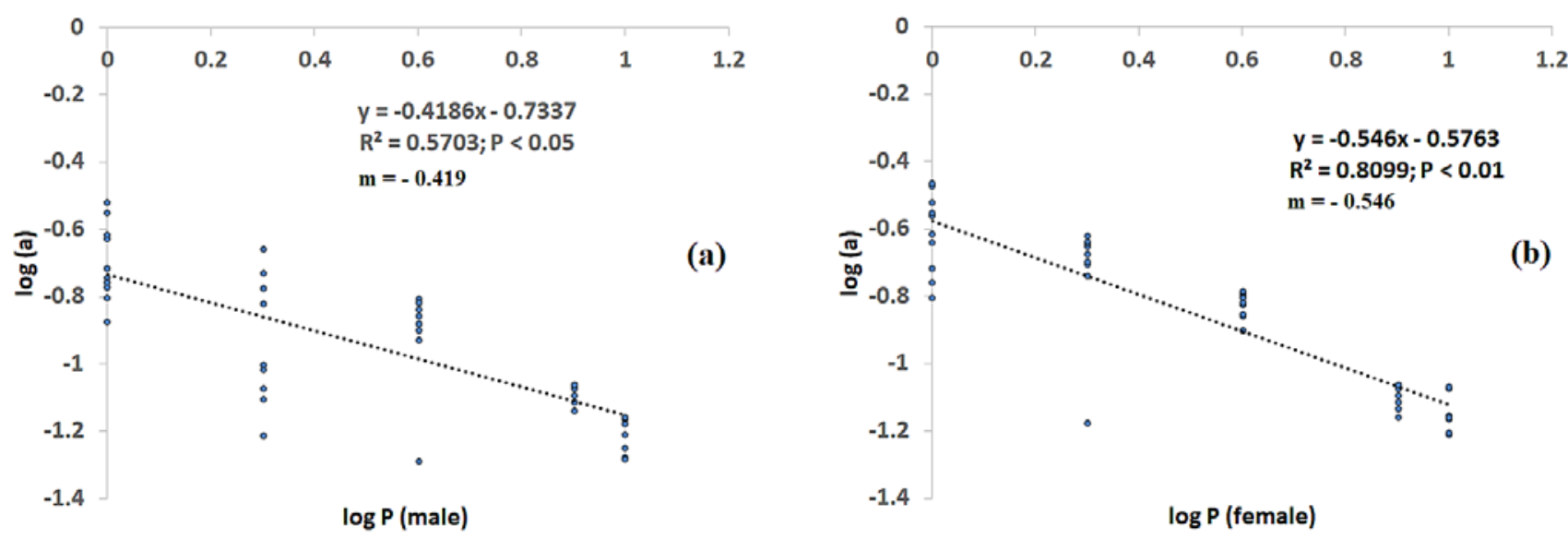

Fig. 3 Mutual interference $(\mathrm{m})$ derived from the relationship between logarithm of predator density and area of discovery for the (a) adult male and (b) female ladybird, $C$. transversalis fed the aphid, $H$. setariae.
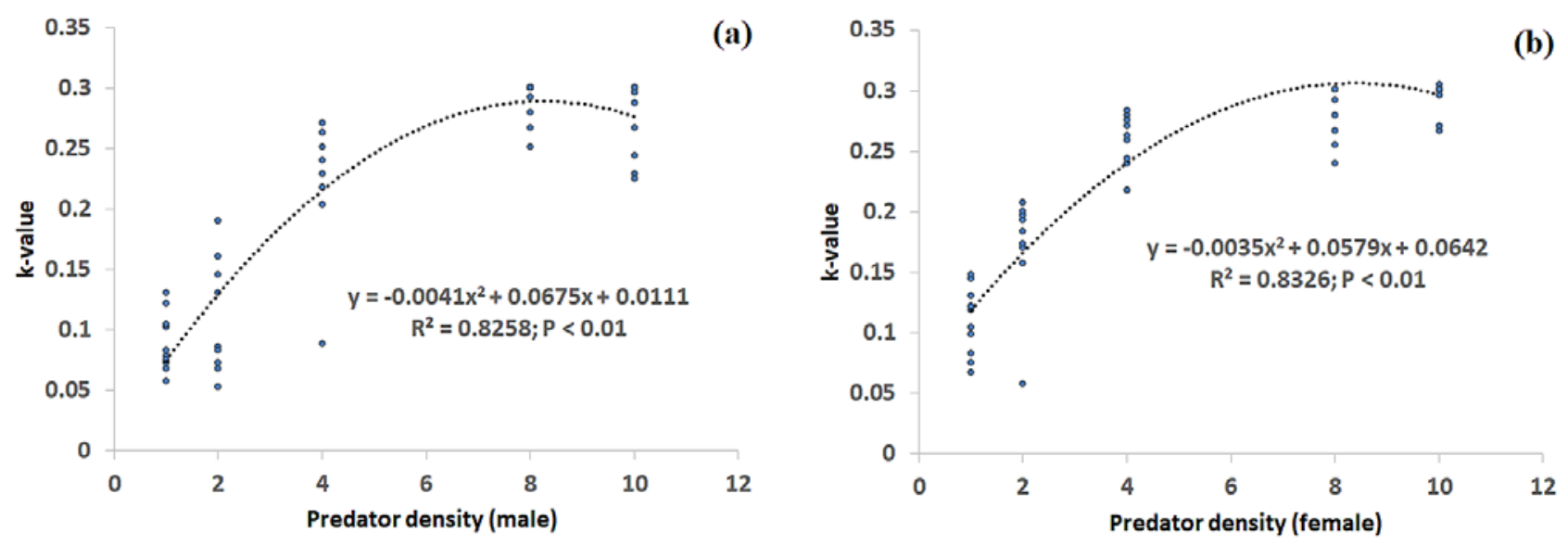

Fig. 4 Relationship between killing power (k-value) and predator density for (a) male and (b) female C. transversalis fed the aphid, H. setariae.

male and female ladybirds were -0.419 and -0.546 , respectively (Fig. 3), while the quest constants were 0.21 and 0.25 , respectively. The killing power of the ladybird denoted by the k-value, increased curvilinearly with increase in predator density (Fig. 4). The mean initial weight $\left(W_{1}\right)$ and the mean final weight $\left(W_{2}\right)$ differed significantly both in the case of adult males and females of C. transversalis (Table 2). The weight gained per predator decreased linearly with increase in predator density of both male and female ladybirds (Fig. 5). 
Table 2 Mean initial weight $\left(\mathrm{W}_{1}\right)$ and Mean Final weight $\left(\mathrm{W}_{2}\right)$ of adult male and female $C$. transversalis at different predator densities when provided with a constant number (200) of the aphid, $H$. setariae as prey.

\begin{tabular}{|l|c|c|c|c|c|c|}
\hline \multirow{2}{*}{$\begin{array}{l}\text { Predator } \\
\text { density }\end{array}$} & \multicolumn{4}{|c|}{ Adult male } & \multicolumn{3}{c|}{ Adult female } \\
\cline { 2 - 7 } & $\begin{array}{c}\text { Mean Initial } \\
\text { weight }\left(\mathrm{W}_{1}\right)\end{array}$ & $\begin{array}{c}\text { Mean Final } \\
\text { weight }\left(\mathrm{W}_{2}\right)\end{array}$ & $\mathrm{t}$-value and probability & $\begin{array}{c}\text { Mean Initial } \\
\text { weight }\left(\mathrm{W}_{1}\right)\end{array}$ & $\begin{array}{c}\text { Mean Final } \\
\text { weight }\left(\mathrm{W}_{2}\right)\end{array}$ & $\mathrm{t}$-value and probability \\
\hline 1 & $13.89 \pm 1.58$ & $16.61 \pm 2.06$ & $\mathrm{t}=-3.32 ; \mathrm{P}<0.01 ;$ d.f. $=16$ & $19.08 \pm 2.74$ & $22.54 \pm 3.12$ & $\mathrm{t}=-2.64 ; \mathrm{P}<0.05 ; \mathrm{d}$.f. $=17$ \\
\hline 2 & $13.93 \pm 0.99$ & $15.99 \pm 1.26$ & $\mathrm{t}=-4.09 ; \mathrm{P}<0.001 ;$ d.f. $=17$ & $2031 \pm 0.69$ & $23.56 \pm 1.08$ & $\begin{array}{c}\mathrm{t}=-7.52 ; \mathrm{P}<0.0001 ; \\
\text { d.f. }=15\end{array}$ \\
\hline 4 & $14.36 \pm 0.51$ & $16.05 \pm 0.75$ & $\mathrm{t}=-5.91 ; \mathrm{P}<0.001 ;$ d.f. $=15$ & $21.74 \pm 1.35$ & $23.62 \pm 0.91$ & $\mathrm{t}=-3.66 ; \mathrm{P}<0.01 ;$ d.f. $=15$ \\
\hline 8 & $14.56 \pm 0.62$ & $15.23 \pm 0.67$ & $\mathrm{t}=-4.02 ; \mathrm{P}<0.001 ;$ d.f. $=17$ & $20.33 \pm 0.29$ & $21.59 \pm 0.34$ & $\begin{array}{c}\mathrm{t}=-9.00 ; \mathrm{P}<0.0001 ; \\
\text { d.f. }=17\end{array}$ \\
\hline 10 & $14.62 \pm 0.64$ & $15.73 \pm 0.70$ & $\mathrm{t}=-4.09 ; \mathrm{P}<0.001 ;$ d.f. $=17$ & $21.71 \pm 0.61$ & $23.03 \pm 0.65$ & $\mathrm{t}=-4.72 ; \mathrm{P}<0.001 ;$ d.f. $=17$ \\
\hline
\end{tabular}

Data are Mean \pm S.D.
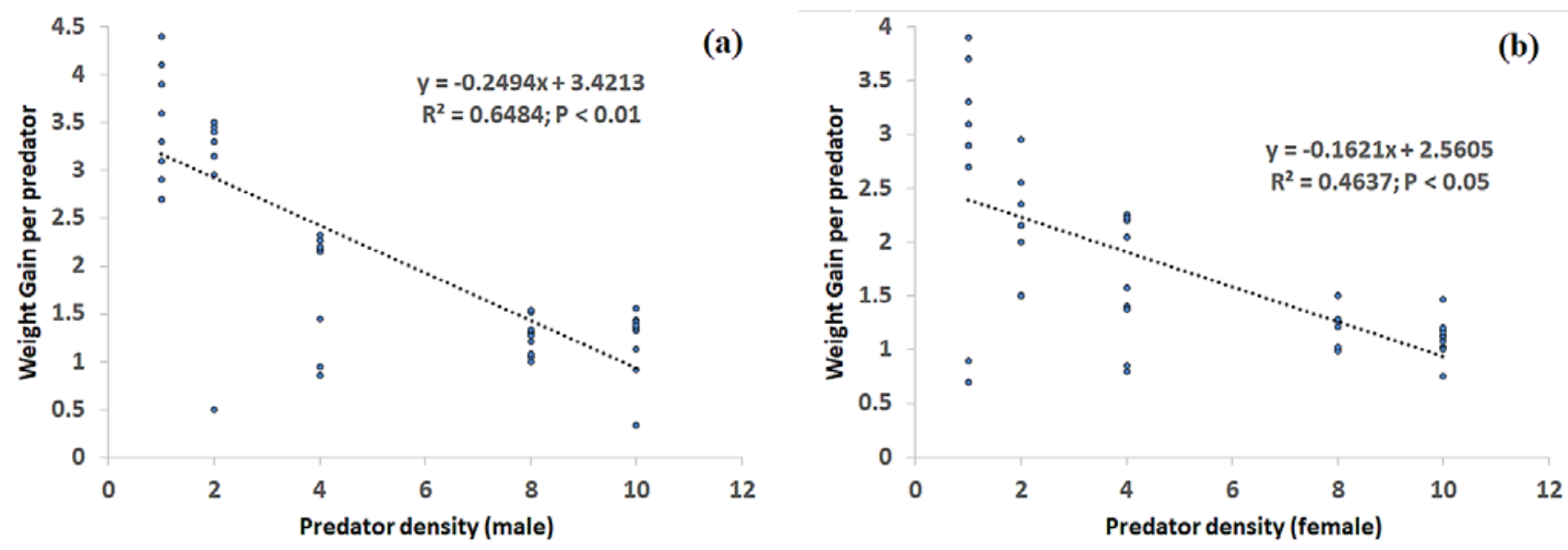

Fig. 5 Relationship between weight-gain per predator of adult (a) male and (b) female C. transversalis subject to different levels of competition for the aphid, H. setariae.

\section{Discussion}

The consumption of prey by adult males and females of $C$. transversalis increased with predator density, indicating that in aggregating they increase prey mortality. However, the rate of increase per predator declined with increase in the number of predators due to mutual interference negatively affecting prey consumption, as reported in previous studies (Bayoumy and Michaud 2012; Bayoumy et al. 2014). The females usually consumed more aphids than the males, which might be attributed to their larger body-size and energy demands for egg production (Lucas et al. 1997; Šipoš et al. 2012). Females of aphidophagous ladybirds need more energy to forage for aphids, search for ovipositional sites and lay eggs, while males just need energy to maintain themselves and to search for females (Hemptinne et al. 1996). Such females tend to search more actively when aphids are scarce or absent than when they are abundant (Evans and Dixon 1986). Hence, female ladybirds locate and consume more aphids than males. In addition, female foraging and prey-consumption may be directly linked to the numerical response, i.e. lay as many eggs as possible, unlike the males whose activities are seemingly dominated by searching for and copulating with females (Evans 2003). Ives (1981) note that the residence time (i.e. time spent in an aphid colony) of the female coccinellids, Coccinella septempunctata L. and Hippodamia variegata (Goeze), is greater than that of males, and aggregation of females was positively correlated with aphid density.

The area of discovery of foraging adults decreased with increase in their density indicating a decline in searching efficiency, the effect of which was greater at high predator-densities implying greater interference between predators. This further indicates that aggregation in a prey patch may result in an increase in mutual interactions that may reduce their effect on prey mortality. Hassell (1971) suggests that each predator might spend less time searching for prey and more time interacting with conspecifics when predators aggregate in patches of prey. We confined the ladybirds in an experimental arena, which resulted in a high incidence of mutual interactions. This indicates that the results may not be relevant to what happens in the field, however, as in patches with a low density of aphids ladybirds may experience a lower incidence of mutual interference with similar outcomes. 
Hence, when there are few conspecific ladybirds present in a patch mutual interference will be low and prey mortality higher and vice versa. Thus, it is important to avoid releasing high numbers of conspecific ladybirds, which might result in high levels of mutual interference and have a negative effect on aphid suppression, decrease in mean weight gain and cannibalism of larvae and pupae. Hence, optimal foraging and the laying eggs (Kindlmann and Dixon 1993) may not occur when ladybirds are abundant, but when scarce it is advantageous in terms of gain in bodyweight and avoidance of cannibalism.

The area of discovery and mutual interference are indicative parameters of the total time spent interacting with other conspecific predators (Rogers and Hassell 1974). Siddiqui et al. (2015) report that mutual interference of slow and fast developing ladybird, Propylea dissecta (Mulsant) were -0.394 and -0.808 , respectively, indicating that fast developers search more efficiently and spend less time interacting with conspecifics. Fast developers tend to eat faster than slow developers and are heavier and lay more eggs than the latter (Singh et al. 2014; Dixon et al. 2016). Mutual interference values for unparasitized and parasitized larvae of Nephus includens (Kirsch) were -0.44 and -0.92 respectively, indicating that interference reduces the foraging capacity of parasitized more than that of unparasitized larvae (Bayoumy and Michaud 2012). Similarly, the mutual interference values for adult male and female $C$. transversalis were -0.43 and -0.72 , respectively, which indicates that females are better foragers and interfere lesser than males.

We recorded a curvilinear increase in aphid consumption with increase in predator density. Bayoumy et al. (2014) note that the killing power of the acarophagous ladybird, Stethorus gilvifrons Mulsant increases with predator aggregation. Adult females consume more aphids than males because they are bigger than males. The mean initial and final adult weights of $C$. transversalis differed significantly indicating that prey consumption is a function of bodyweight. Ladybird abundance in an aphid-resource rich environment may result in an increase in adult body-size. Individual ladybirds vary in body-size for dietary and genetic reasons. It is widely held that body-size is positively correlated with fitness and is driven by diet (Stearns 1992). Hence, it is likely that the heaviest adults will have a selective advantage. However, small generalist ladybirds, which feed on a wide range of species of aphids, may have an advantage when aphids are scarce (Sloggett 2008). We also recorded that regardless of gender, predator abundance tends to be associated linearly with decrease in the weight gained per predator, which was significantly greater when the number of predators was low, which might indicate that mutual interference was lower and prey consumption per predator higher than when number of predators was high. Hence, selection should favour adults, which as described by Dixon (2000) are able to avoid laying eggs in patches of aphids already being exploited by ladybirds as it not only results in an increase fitness but also a reduction in mutual interference between the larvae. However, further research is needed to address this issue.

It is concluded that (i) the searching efficiency of $C$. transversalis decreased with increase in predator density, (ii) mutual interference negative affected prey consumption especially that of adult males, (iii) the difference in the aphid consumption of females and males became more skewed in favour of females with increase in predator density, and (iv) the gain in bodyweight per predator decreased with increase in the number of ladybirds.

\section{Acknowledgements}

Authors thank Prof. A.F.G. Dixon, Emeritus Professor, School of Biological Sciences, University of East Anglia, Norwich, UK and Prof. Pavel Kindlmann, Charles University, Prague, Czech Republic for improving the English and providing fruitful comments and suggestions, Dr. A. Betsy for improving the draft at the initial stage, and Science and Engineering Research Board, Department of Science and Technology, New Delhi for funding this research (EMR/2016/006296).

\section{REFERENCES}

Al-Deghairi MA, Abdel-Baky NF, Fouly MH, Ghanim NM (2014) Foraging behavior of two coccinellid species (Coleoptera: Coccinellidae) fed on aphids. J Agric Urban Entomol 30: 12-24.

Bayoumy MH (2011) Foraging behavior of the coccinellid Nephus includens (Coleoptera: Coccinellidae) in response to Aphis gossypii (Hemiptera: Aphididae) with particular emphasis on larval parasitism. Environ Entomol 40: 835-843.

Bayoumy MH, Michaud JP (2012) Parasitism interacts with mutual interference to limit foraging efficiency in larvae of $\mathrm{Ne}$ phus includens (Coleoptera: Coccinellidae). Biol Cont 62: 120-126.

Bayoumy MH, Osman MA, Michaud JP (2014) Host plant mediates foraging behavior and mutual interference among adult Stethorus gilvifrons (Coleoptera: Coccinellidae) preying on Tetranychus urticae (Acari: Tetranychidae). Environ Entomol 43: 1309-1318.

Brown JH, Sibly RM (2006) Life-history evolution under a production constraint. Proc Nat Acad Sci USA 103: 17595-17599.

Dixon AFG (2000) Insect predator-prey dynamics, ladybird beetles and biological control. Cambridge University Press, Cambridge.

Dixon AFG (2007) Body size and resource partitioning in ladybirds. Popul Ecol 49: 45-50.

Dixon AFG, Sato S, Kindlmann P (2016) Evolution of slow and fast development in predatory ladybirds. J Appl Ent 140: 103-114.

Evans EW (2003) Searching and reproductive behaviour of female aphidophagous ladybirds (Coleoptera: Coccinellidae): a review. Eur J Entomol 100: 1-10.

Evans EW, Dixon AFG (1986) Cues for Oviposition by Ladybird Beetles (Coccinellidae): Response to Aphids. J Anim Ecol 55: 1027-1034.

Fathipour Y, Maleknia B, Bagheri A, Soufbaf M, Reddy GVP (2020) Functional and numerical responses, mutual interference, and 
resource switching of Amblyseius swirskii on two-spotted spider mite. Biol Cont 146: 104266.

Hassell MP (1971) Mutual interference between searching insect parasites. J Anim Ecol 40: 473-486.

Hassell MP, Varley GC (1969) New inductive population model for insect parasites and its bearing on biological control. Nature 223: 1133-1137.

Hemptinne JL, Dixon AFG, Lognay G (1996) Searching behaviour and mate recognition by males of the two-spot ladybird beetle, Adalia bipunctata. Ecol Ent 21: 165-170.

Hodek I, van Emden HF, Honek I (2012) Ecology and behavior of the ladybird beetles (Coccinellidae). Wiley-Blackwell, Oxford, UK.

Holling CS (1959) Some characteristics of simple types of predation and parasitism. Can Ent 91: 385-398.

Ives PM (1981) Estimation of coccinellid numbers and movement in the field. Can Ent 113: 981-997.

Kajita Y, Evans EW (2010) Relationships of body size, fecundity, and invasion success among predatory lady beetles (Coleoptera: Coccinellidae) Inhabiting alfalfa fields. Ann Ent Soc Amer 103: 750-756.

Kale P, Bisen A, Naikwadi B, Bhure K, Undirwade DB (2020) Diversity study of aphids and associated predatory fauna occurred in major Kharif and Rabi crop ecosystems of Akola, Maharashtra, India. Int J Chem Studies 8: 3868-3876.

Kindlmann P, Dixon AFG (1993) Optimal foraging in ladybird beetles (Coleoptera: Coccinellidae) and its consequences for their use in biological control. Eur J Entomol 90: 443-450.

Kindlmann P, Dixon AFG (1999) Generation Time Ratios - Determinants of Prey Abundance in Insect Predator-Prey Interactions. Biol Cont 16: 133-138.

Kindlmann P, Dixon AFG (2001) When and why top-down regulation fails in arthropod predator-prey systems. Basic Appl Ecol 2: 333-340.

Kindlmann P, Dixon AFG (2010) Modelling Population Dynamics of Aphids and Their Natural Enemies. In: Kindlmann P, Dixon AFG, Michaud JP (eds) Aphid biodiversity under environmental change, Patterns and Processes. Springer Dordrecht Heidelberg London New York, pp 1-20.

Kindlmann P, Stipkova Z, Dixon AFG (2020) Generation time ratio, rather than voracity, determines population dynamics of insect - natural enemy systems, contrary to classical Lotka-Volterra models. Eur J Environ Sci 10: 133-140.

Kindlmann P, Yasuda H, Kajita Y, Sato S, Dixon AFG (2015) Predator efficiency reconsidered for a ladybird-aphid system. Frontiers Ecol Evol 3: 1-5.

Legrand A, Barbosa P (2003) Plant Morphological Complexity Impacts Foraging Efficiency of Adult Coccinella septempunctata L. (Coleoptera: Coccinellidae). Environ Entomol 32: 1219-1226.

Lucas E, Coderre D, Vincent C (1997) Voracity and feeding preference of two aphidophagous coccinellids fed on Aphis citricola and Tetranychus urticae. Ent Exp Applic 85: 151-159.

Maurice N, Pervez A, Kumar A, Ramteke PW (2011) Duration of Development and Survival of larvae of Coccinella transversalis fed on essential and alternative foods. Eur J Environ Sci 1:24-27.

Michaud JP, Bista M, Mishra G, Omkar (2013) Sexual activity diminishes male virility in two Coccinella species: consequences for female fertility and progeny development. Bull Ent Res 103: 570-577.

Nicholson AJ, Bailey VA (1935) The balance of animal populations. Proc Zool Soc London 105: 551-598.

Omkar, Gupta AK, Pervez A (2005a) Attack, escape and predation rates of the larvae of two aphidophagous ladybirds during conspecific and heterospecific interactions. Biocont Sci Technol 13: 295-305.
Omkar, James BE (2004) Influence of prey species on immature survival, development, predation and reproduction of Coccinella transversalis Fabricius (Col., Coccinellidae). J Appl Ent 128: 150-157.

Omkar, Pervez A (2004a) Functional and numerical responses of Propylea dissecta (Mulsant) (Col., Coccinellidae). J Appl Ent 128: 140-146.

Omkar, Pervez A (2004b) Predaceous coccinellids in India: Predator-prey catalogue. Oriental Insects 38: 27-61.

Omkar, Pervez A (2011) Functional response of two aphidophagous ladybirds searching in tandem. Biocont Sci Technol 21: 101-111.

Omkar, Pervez A (2016) Ladybird beetles. In Omkar (ed) Ecofriendly Pest Management for Food Security (pp 281-310), Academic Press, London, UK.

Omkar, Pervez A, Gupta AK (2005b) Egg cannibalism and intraguild predation in two co-occurring generalist ladybirds: a laboratory study. Int J Trop Insect Sci 25: 259-265.

Ooi PAC (1980) Laboratory studies of Diadegma cerophagus (Hym.: Ichneumonidae), a parasite introduced to control Plutella xylostella (Lepidoptera: Hyponomeutidae) in Malaysia. Entomophaga 25: 249-259.

Papanikolaou NE, Demiris N, Milonas PG, Preston S, Kypraios T (2016) Does mutual interference affect the feeding rate of aphidophagous coccinellids? A modeling perspective. PLoS ONE 11: e0146168. doi: 10.1371/journal.pone.0146168.

Pervez A, Omkar, Harsur MM (2020) Coccinellids on crops: Nature's gift for farmers. In: Chakravarty AK (ed) Innovative pest management approaches for the 21st Century: Harnessing automated unmanned technologies, Springer International Publisher, Singapore, pp 429-460. doi: 10.1007/978-981-15-0794 $-6 \_21$.

Pervez A, Singh PP, Bozdogan H (2018) Ecological perspective of the diversity of functional responses. Eur J Environ Sci 8: 5-9.

Pervez A, Yadav M (2018) Foraging behaviour of predaceous ladybird beetles: a review. Eur J Environ Sci 8: 10-16.

Rattanpun W (2017). Banker plant system using Hysteroneura setariae (Thomas) (Hemiptera: Aphididae) as a non-pest prey to build up the lady beetle populations. J Asia Pacific Entomol 20: 437-440.

Rogers DJ, Hassell MP (1974) General models for insect parasite and predator searching behaviour inference. J Anim Ecol 43: $239-253$.

SAS 9.0 (2002) SAS/Stat Version 9, SAS Institute Inc., Cary, NC, USA.

Siddiqui A, Omkar, Paul SC, Mishra G (2015) Predatory responses of selected lines of developmental variants of ladybird, Propylea dissecta (Coleoptera: Coccinellidae) in relation to increasing prey and predator densities. Biocont Sci Technol 25: 992-1010.

Singh N, Mishra G, Omkar (2014) Does temperature modify slow and fast development in two aphidophagous ladybirds? J Thermal Biol 39: 24-31.

Sloggett JJ (2008) Weighty matters: Body size, diet and specialization in aphidophagous ladybird beetles (Coleoptera: Coccinellidae). Eur J Entomol 105: 381-389.

Stearns SC (1992) The evolution of life histories. Oxford University Press, Oxford.

Šipoš J, Kvastegård E, Baffoe KO, Sharmin K, Glinwood R, Kindlmann P (2012) Differences in the predatory behaviour of male and female ladybird beetles (Coccinellidae). Eur J Environ Sci 2: $51-55$.

Varley GC, Gradwell GR, Hassell MP (1973) Insect population ecology: An analytical approach. University of California Press, Berkeley and Los Angeles, CA. 